\title{
Virstatin inhibits biofilm formation and motility of Acinetobacter baumannii
}

\author{
Yassine Nait Chabane ${ }^{1,2}$, Mohamed Ben Mlouka ${ }^{1,2}$, Stéphane Alexandre ${ }^{1,2}$, Marion Nicol $^{1,2}$, Sara Marti ${ }^{1,2}$, \\ Martine Pestel-Caron ${ }^{1,3}$, Jordi Vila ${ }^{4}$, Thierry Jouenne ${ }^{1,2}$ and Emmanuelle Dé $e^{1,2^{*}}$
}

\begin{abstract}
Background: Acinetobacter baumannii has emerged as an opportunistic nosocomial pathogen causing infections worldwide. One reason for this emergence is due to its natural ability to survive in the hospital environment, which may be explained by its capacity to form biofilms. Cell surface appendages are important determinants of the A. baumannii biofilm formation and as such constitute interesting targets to prevent the development of biofilm-related infections. A chemical agent called virstatin was recently described to impair the virulence of Vibrio cholerae by preventing the expression of its virulence factor, the toxin coregulated pilus (type IV pilus). The objective of this work was to investigate the potential effect of virstatin on A. baumannii biofilms.

Results: After a dose-response experiment, we determined that $100 \mu \mathrm{M}$ virstatin led to an important decrease (38\%) of biofilms formed by A. baumannii ATCC17978 grown under static mode. We demonstrated that the production of biofilms grown under dynamic mode was also delayed and reduced. The biofilm susceptibility to virstatin was then tested for 40 clinical and reference A. baumannii strains. $70 \%$ of the strains were susceptible to virstatin (with a decrease of 10 to $65 \%$ ) when biofilms grew in static mode, whereas $60 \%$ of strains respond to the treatment when their biofilms grew in dynamic mode. As expected, motility and atomic force microscopy experiments showed that virstatin acts on the A. baumannii pili biogenesis.
\end{abstract}

Conclusions: By its action on pili biogenesis, virstatin demonstrated a very promising antibiofilm activity affecting more than $70 \%$ of the A. baumannii clinical isolates.

Keywords: Pellicle, Protein-protein interactions, Type IV pili, Virstatin

\section{Background}

Acinetobacter baumannii, a microorganism with a worldwide epidemic spread, causes a wide range of infections, including pneumonia and blood-stream infections. This increasing threat in hospitals is mainly due to the occurrence of multidrug-resistant strains, associated with the real problem of eradication in the hospital wards [1]. Biofilm formation may facilitate the environmental survival of $A$. baumannii by conferring resistance to antibiotics, desiccation or nutritional stress and explain the success of particular strains in hospitals [2,3]. Several factors have been proved to play a role in this biofilm formation or maturation, like the poly- $\beta-(1-6)-\mathrm{N}$-acetyl glucosamine

\footnotetext{
* Correspondence: emmanuelle.de@univ-rouen.fr

${ }^{1}$ Normandie University, Caen, France

2Laboratory "Polymères, Biopolymères, Surfaces", UMR 6270 \& FR 3038 CNRS, IRIB, University of Rouen, Mont-Saint-Aignan, Cedex 76821, France

Full list of author information is available at the end of the article
}

extracellular polysaccharide, the biofilm-associated protein, the autotransporter Ata or the systems of protein glycosylation [4-7]. In addition, extracellular appendages are often involved in different stages of bacterial biofilm [8] as exemplified by the $c s u A / B A B C D E$ chaperon-usher system, coding for fimbriae, and required for initial steps of $A$. baumannii biofilm development $[6,9,10]$. Recent findings have also demonstrated that more than one cell surface appendages system may be involved in the maintenance of the biofilm structure, especially when the biofilm is formed at the air-liquid interface [11]. Finally, the presence of a type IV pili system and its involvement in motility was recently described in A. baumannii [12]. It could also play a role in biofilm development (initial adhesion, microcolonies formation and in maturation, last step of biofilm formation) as demonstrated for other bacterial species $[8,13]$. Therefore, the contribution of extracellular

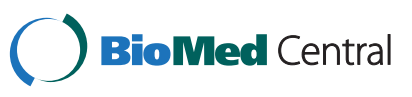

(c) 2014 Nait Chabane et al.; licensee BioMed Central Ltd. This is an Open Access article distributed under the terms of the Creative Commons Attribution License (http://creativecommons.org/licenses/by/2.0), which permits unrestricted use, distribution, and reproduction in any medium, provided the original work is properly credited. The Creative Commons Public Domain Dedication waiver (http://creativecommons.org/publicdomain/zero/1.0/) applies to the data made available in this article, unless otherwise stated. 
appendages to the biofilm structuration makes them very attractive as therapeutic targets [14].

In this study, we experienced this new approach by testing the use of the chemical agent virstatin. This small organic molecule has been demonstrated to inhibit Vibrio cholerae virulence and its orogastric administration would protect infant mice from $V$. cholerae intestinal colonization $[15,16]$. Virstatin acted in preventing expression of the two major Vibrio cholerae virulence factors, cholera toxin and the toxin coregulated pilus (a type IV pilus, T4P). It would disrupt protein-protein interactions, i.e. the dimerization of the transcriptional regulator ToxT, stopping thus the activation of $c t x$ and $t c p$ genes [15,16].

We present here the efficacy of the virstatin as an inhibitor of the pili system synthesis to prevent $A$. baumannii biofilm formation.

\section{Methods}

Bacterial strains and MICs determination

We used A. baumannii ATCC 17978 and ATCC 19606 as reference strains, as well as 38 clonally unrelated $A$. baumannii clinical isolates, among which multidrugresistant (MDR) and extensively drug-resistant (XDR) strains $[2,17]$. Nineteen clinical isolates formed biofilm on solid support and the remaining 19 isolates had the ability to form a pellicle [18]. Determination of MICs of virstatin (4-[N-(1,8-naphthalimide)]-n-butyric acid; Bachem, Weil am Rhein, Germany) solubilized in dimethyl sulfoxide (DMSO, Sigma, Saint Louis, USA) was performed by the microdilution method as described by Wiegand et al. [19].

\section{Virstatin effect on biofilms formed in static mode}

A. baumannii biofilms were grown on 24-wells plates in Mueller Hinton $(\mathrm{MH})$ broth with or without virstatin added at 20,50 or $100 \mu \mathrm{M}$ using DMSO as control. Plates were incubated for $24 \mathrm{~h}$ at $37^{\circ} \mathrm{C}$ without shaking. Attached cells were quantified by the protocol described by O'Toole and Kolter [20] or counted after their detachment by sonication. $25 \mu \mathrm{L}$ were plated on $\mathrm{MH}$ agar and Colony Forming Units (CFU) were counted after $24 \mathrm{~h}$ of additional growth at $37^{\circ} \mathrm{C}$. For testing the dispersing effect of virstatin, biofilms were grown for $24 \mathrm{~h}$ then

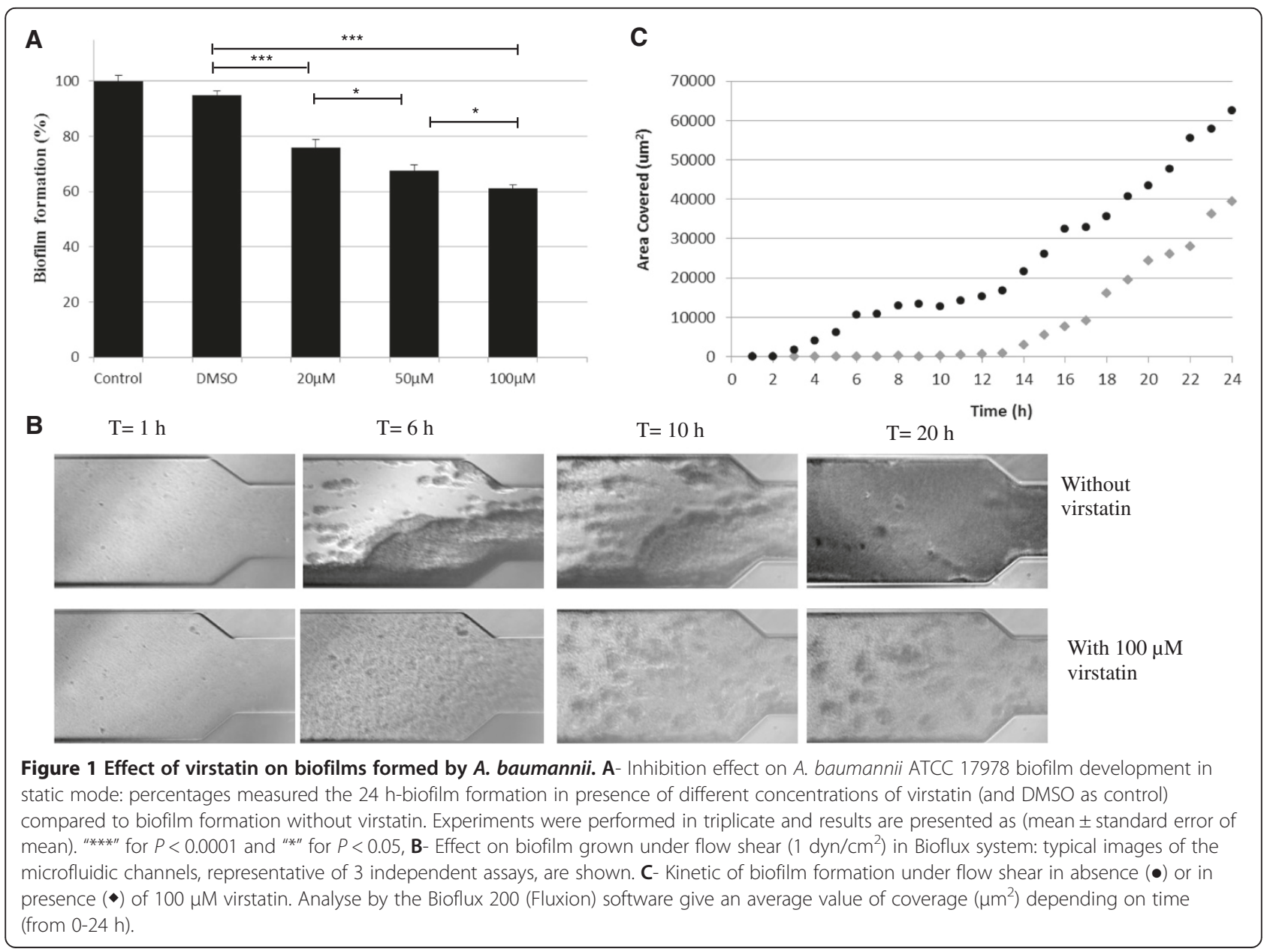


challenged with increasing concentrations of virstatin (from 25 to $400 \mu \mathrm{M}$ ). Attached cells were similarly quantified after $24 \mathrm{~h}$ of additional growth.

All experiments were performed at least in triplicate. One way ANOVA was used to assess significant differences between a biofilm growth with and without virstatin. All data were statistically analyzed using Prism Graph Pad 5.

\section{Virstatin effect on biofilms formed in dynamic mode}

The effect of virstatin on biofilms formed in dynamic mode was estimated with the BioFlux device (Fluxion Biosciences, South San Francisco, CA) as described by Benoit et al. [21] with some modifications. This system consists of a network of microfluidic laminar flow channels in which the growth of biofilms is controlled by shear force. The microfluidic channels (depth, $70 \mu \mathrm{m}$; width, $370 \mu \mathrm{m}$ in PDMS : PolyDiMéthylSiloxane) were wetted with $\mathrm{MH}$ medium and inoculated with $10^{7}$ CFU.mL ${ }^{-1}$ of $A$. baumannii ATCC 17978 or of the other 39 strains. Following $1 \mathrm{~h}$ of incubation for cell attachment at $37^{\circ} \mathrm{C}, 1 \mathrm{~mL}$ fresh $\mathrm{MH}$ broth containing or not $100 \mu \mathrm{M}$ virstatin was pumped at a flow rate of $0.3 \mathrm{dyn} / \mathrm{cm}^{2}$ from inlet wells through the channels to outlet wells. To obtain images, A. baumannii strains were grown for $24 \mathrm{~h}$ with a flow rate of $1 \mathrm{dyn} / \mathrm{cm}^{2}$. During biofilm formation, images were obtained using an inverted video-microscope (Leica DM IRBE), a digital camera (CoolSNAP Fx), and treated by Metamorph 7.0 software. Biofilm quantification was performed by image analysis using the Bioflux 200 software and the 'area coverage' module in 'greyscale' mode. The amount of sessile bacterial covering the flow cells was estimated in a defined and representative window, by an average value of coverage $\left(\mu \mathrm{m}^{2}\right)$ depending on time (from 0-24 h). These values were then compared in absence or presence of $100 \mu \mathrm{M}$ virstatin.

\section{Motility experiments}

Motility of all $A$. baumannii strains was tested on polystyrene Petri dishes containing $10 \mathrm{~g} / \mathrm{L}$ tryptone, $5 \mathrm{~g} / \mathrm{L}$ $\mathrm{NaCl}$ with $0.3 \%$ agar (TSA; Difco) supplemented with $100 \mu \mathrm{M}$ of virstatin or with the same volume of DMSO and incubated at $37^{\circ} \mathrm{C}$ overnight [22].

\section{Atomic force microscopy (AFM)}

A. baumannii ATCC 17978 pellicles were transferred to collodion-coated glass slides after $8 \mathrm{~h}$ growth in MH broth supplemented or not with $100 \mu \mathrm{M}$ of virstatin [11]. AFM imaging was performed as described in Marti et al. [11].

\section{Results}

Virstatin effect on A. baumannii growth in planktonic mode

We first examined the toxicity of virstatin on planktonically growing A. baumannii ATCC 17978 by generating growth curves with and without this compound and by counting CFU after addition of different concentrations of virstatin (Additional file 1: Figure S1-A\&B). Neither virstatin nor its solvent (DMSO) inhibited A. baumannii growth at concentrations used in next steps of this study. The MIC of virstatin was finally measured at $1.6 \mathrm{mM}$.

\section{Virstatin effect on $A$. baumannii sessile bacteria}

To investigate the preventing effect of virstatin on biofilm growth in static mode, we measured A. baumannii ATCC 17978 biofilm production at varying virstatin concentrations. This quantitative determination was monitored by crystal violet colorimetric assay. Figure 1A shows clearly that virstatin exhibited an anti-biofilm activity, which was optimal for $100 \mu \mathrm{M}$ with $38 \%$ biofilm formation inhibition. These data were confirmed by bacterial counting within the biofilms depending on virstatin

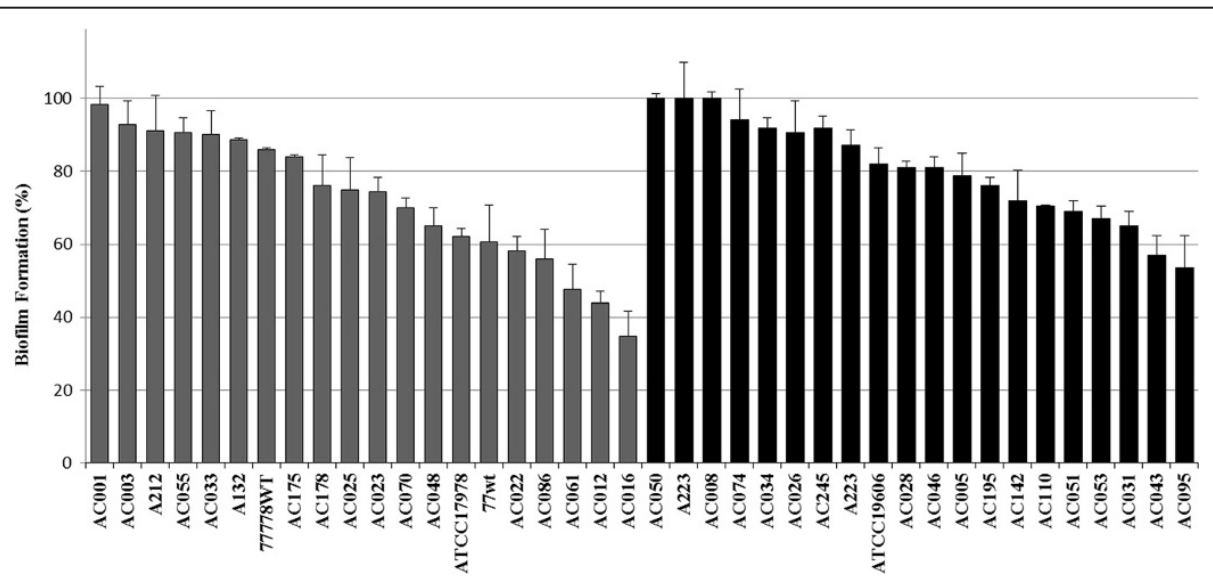

Figure 2 Virstatin activity on biofilm formation by $A$. baumannii clinical isolates: Percentages measured the 24 h-biofilm formation in presence of $100 \mu \mathrm{M}$ virstatin compared to biofilm formation without virstatin (but DMSO as control). 100\% denoted no activity of virstatin. A. baumannii strains forming biofilm on solid supports in black bars ( $\mathbf{a})$, strains forming pellicle in dark grey bars ( $\square$ ). 

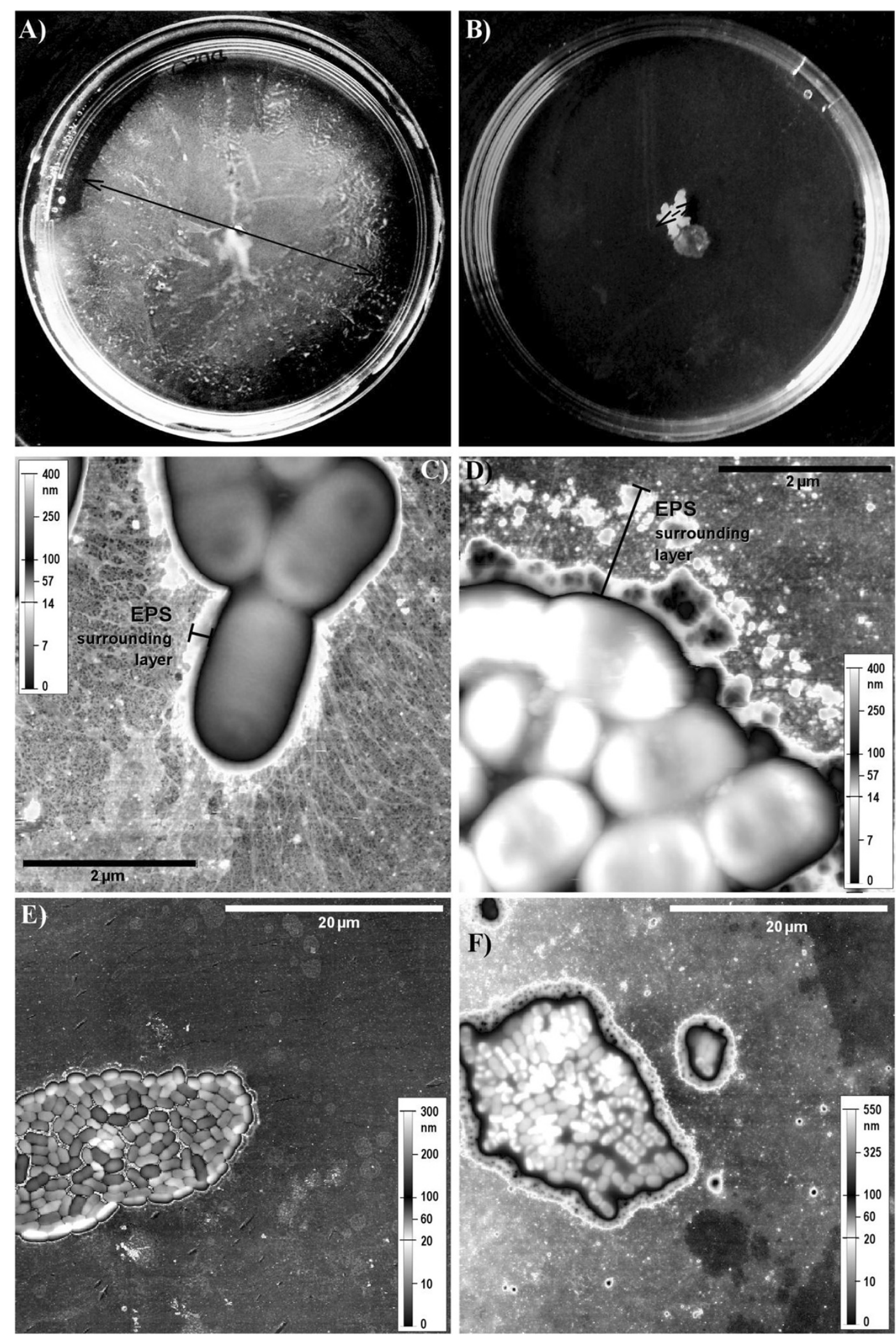

Figure $\mathbf{3}$ (See legend on next page.) 
(See figure on previous page.)

Figure 3 Virstatin affects bacterial motility and pili production. A\&B- Plates of motility of A. baumannii ATCC 17978 strain in presence (B) or absence (A) of virstatin in semi-solid $0.3 \%$ TSA after $24 \mathrm{~h}$ growth at $37^{\circ} \mathrm{C}$. Typical plates are shown. The diameter of the motility zone decreased when medium is supplemented with $100 \mu \mathrm{M}$ virstatin. The experiments were performed in triplicate. C-F - AFM images of A. baumannii ATCC 17978 waterfacing side pellicles after $8 \mathrm{~h}$ growth: C\&E without virstatin; D\&F with $100 \mu \mathrm{M}$ virstatin. Topographic representation using an uncommon scale made to emphasize the bacterial pili and the 'EPS' (extrapolymeric substances) surrounding layer.

concentrations (Additional file 1: Figure S1-B). We then examined the dispersing effect of virstatin on preformed biofilms. After growth for $24 \mathrm{~h}$, biofilms were challenged by different concentrations of virstatin. Additional file 2 : Figure S2 shows slight biofilm dispersion (12\% for $400 \mu \mathrm{M})$ whatever the virstatin concentration. Therefore, virstatin exerted a marked inhibitory effect on A. baumannii biofilm formation but a weak dispersing effect on preformed biofilms.

We also investigated the effect of virstatin on biofilms formed in dynamic mode under flow shear, using the Bioflux microfluidic device. Figure $1 \mathrm{~B}$ shows light micrographs taken from 0 to $24 \mathrm{~h}$ after the flow was initiated in the presence or absence of $100 \mu \mathrm{M}$ virstatin. At $6 \mathrm{~h}$, the micrographs showed a reduction of biofilm formation within the microfluidic channel irrigated by broth enriched in virstatin. After $20 \mathrm{~h}$, in absence of virstatin, the channel was nearly filled by biofilm, whereas broth loaded with virstatin could still freely flow through the channel. The Figure $1 \mathrm{C}$ showed the kinetic of biofilm formation within the channels for both conditions. It clearly demonstrated that virstatin induced a time lag of nearly 10 hours for biofilm formation and that the biofilm production is reduced after $24 \mathrm{~h}$. These data confirmed an antibiofilm action of virstatin within the first steps of biofilm formation.

\section{Virstatin effect on biofilms formed by clinical isolates}

To assess more broadly the anti-biofilm activity of virstatin, we tested this molecule on different $A$. baumannii clinical isolates as well as on the two reference strains. We examined a panel of 20 isolates forming pellicle and 20 other strains forming only biofilm on solid support [18]. As shown by Figure 2, 70\% of clinical isolates presented at least a $10 \%$ decrease in their ability to form a biofilm. This decrease reached more than 65\% for $100 \mu \mathrm{M}$ virstatin. It should be noticed that the activity of virstatin was more marked on strains forming pellicle (75\% of strains with a decrease from 10 to $65 \%$ ) than on strains forming only biofilm on solid support (65\% of strains with a decrease from 10 to $47 \%$ ). The activity of virstatin was also examined on biofilms grown in dynamic mode. If all the tested strains were able to develop a biofilm in dynamic growth mode, virstatin could induce a time lag only for $60 \%$ of strains (Additional file 3 : Table S1) and its activity was also more marked on strains forming pellicle (75\%) than on strains forming biofilm on solid support (45\%).

\section{Virstatin affects bacterial motility and pili production}

As virstatin may affect pili production, we performed motility assays. $0.3 \%$ TSA plates containing or not $100 \mu \mathrm{M}$ virstatin were inoculated by A. baumannii ATCC 17978 [12]. Figure $3 \mathrm{~A} \& \mathrm{~B}$ shows that virstatin significantly inhibited bacterial migration. This motility assay was performed for all the strains (Additional file 3: Table S1) and the data showed that over the 30 strains that were mobile, $60 \%$ underwent a decrease of their motility.

In order to check the presence of pili after virstatin action, the pellicles of $A$. baumannii ATCC 17978 were examined by AFM. In absence of virstatin, observation of the water-facing side of the pellicles revealed the significant presence of pili ( 0.5 to $2 \mu \mathrm{m}$ in length) around bacteria, which were located on the border of the colonies (Figure $3 \mathrm{C}$ ). In contrast when bacteria grew with virstatin, the amount of pili drastically decreased (Figure 3D). Moreover, we observed a layer surrounding bacteria, the average height and width of which were greater in presence (height: $100 \mathrm{~nm}$, width: $1-1.5 \mu \mathrm{m}$ ) than in absence of virstatin (height: $50 \mathrm{~nm}$, width: $0.1 \mu \mathrm{m}$, Figure 3C \& D). This was most likely extrapolymeric substances (EPS) overproduced in presence of virstatin. At a lower resolution, images showed strong differences between both pellicles (Figure 3E \& F). The pellicle formed in absence of virstatin was quite dense and was formed of a single bacterial layer, giving a colony mean height of $(0.20 \pm 0.05)$ $\mu \mathrm{m}$. In presence of virstatin, the pellicle appeared less dense and formed with more than one layer of bacteria. In this case, the colony was about $(0.50 \pm 0.05) \mu \mathrm{m}$ in height.

\section{Discussion}

Targeting essential protein-protein interactions in bacterial function is a very promising but challenging therapeutic approach which is increasingly developed $[14,15]$. In this context, small organic molecules (ring fused 2-pyridones) were tested as pilicide or curlicide on uropathogenic Escherichia coli (UPEC) with success. In targeting either type 1 pili or amyloid fibers biogenesis, these compounds can prevent biofilm formation and attenuate UPEC virulence [14]. Virstatin is similarly used to decrease the expression of T4P which are virulence factors in $V$. cholerae $[15,16]$. 
In this study, we demonstrated that virstatin presents also an interesting antibiofilm activity as it could reduce by $65 \%$ the biofilm production in some $A$. baumannii clinical isolates and is active on more than $70 \%$ of the tested strains. Virstatin remained also active against biofilms formed under flow shear inducing clearly a delay of the development of this type of biofilm. These results are in favor of its action on pili biogenesis. Indeed, these cell surface appendages are known to be involved in the first stages of biofilm development promoting, initial adhesion and surface colonization but also microcolonies formation [8]. Thus the decrease of virstatin activity at a later phase of biofilm development ( $48 \mathrm{~h}$ ) is not surprising, as pili expression may not be required. Moreover, the AFM observations confirmed the hypothesis suggesting an inhibitory effect of virstatin on the biogenesis of pili: they pointed out a drastic under-production of these appendages in the presence of the molecule (Figure 3C \& D). Finally, motility experiments demonstrated that virstatin clearly affected the migration of $A$. baumannii on semisolid surface. This motility has been examined by Clemmer and colleagues [12] who showed that the loss of pilT, a gene involved in twitching mediated by T4P, resulted in a $54 \%$ reduction in motility of non-flagellar A. baumannii. In addition, AFM micrographs showed the overexpression of EPS in biofilms grown with virstatin. Recently Wang et al. [23] demonstrated that if deletion of T4P in Pseudomonas aeruginosa resulted in a reduction of biofilm biomass in flow cell and in pellicles, it concomitantly resulted in an overproduction of the Psl polysaccharide in the microcolonies. Overall, these results are in favor of an action of virstatin on T4P pili biogenesis.

\section{Conclusions}

The emergence of $A$. baumannii as one of the most problematic nosocomial pathogen has made necessary the development of new strategies to impair its ability to persist in hospital environment. Here, we have tested a strategy based on the prevention of the pili biosynthesis to reduce the A. baumannii biofilm production. This was successful with the use of a small organic compound, the virstatin, which demonstrated an activity on $70 \%$ of the clinical isolates with a decrease in biofilm production that could reach $65 \%$.

\section{Additional files}

Additional file 1: Figure S1. Virstatin effect on A. baumannii ATCC 17978 growth in planktonic and biofilm modes. A- Growth curves of A. baumannii in $\mathrm{MH}$ broth $(\square), \mathrm{MH}$ broth with $0.5 \%$ DMSO (volume used for the addition of $100 \mu \mathrm{M}$ virstatin) $(\diamond)$, or $\mathrm{MH}$ broth with $100 \mu \mathrm{M}$ virstatin $(\triangle)$. B- A. baumannii colony forming units after a $24 \mathrm{~h}$ planktonic ( ) and biofilm (-) growth depending on virstatin concentrations. Curves are given as an average of 3 replicates.
Additional file 2: Figure S2. Dispersing effect of virstatin. Virstatin added at $100 \mu \mathrm{M}$ on $24 \mathrm{~h}$ preformed biofilms. Quantification of biofilm biomass was made by crystal violet staining after additional $24 \mathrm{~h}$ growth. " $*$ *" for $P<0.05$.

Additional file 3: Table S1. Virstatin effect on A. baumannii clinical isolates.

\section{Competing interests}

The authors declare that they have no competing interests.

\section{Authors' contributions}

YN-C, TJ, ED conceived and designed the experiments. YN-C, MB-M, MP-C, SM, SA, MN performed the experiments. YN-C, SA, TJ, JV, ED analyzed the data. MP-C, SM, SA, JV contributed to materials/technical support. ED wrote the paper. All authors read and approved the final manuscript.

\section{Acknowledgements}

We thank the Spanish Group for the Study of Nosocomial Infections (GEIH) to provide us A. baumannii clinical isolates, the Primacen microscopy Platform for their technical help and Dr. G.A. Junter for helpful discussions. YN-C. has a doctoral fellowship from the Haute-Normandie region and MBM. from "Vaincre La Mucoviscidose".

\section{Author details}

${ }^{1}$ Normandie University, Caen, France. ${ }^{2}$ Laboratory "Polymères, Biopolymères, Surfaces", UMR 6270 \& FR 3038 CNRS, IRIB, University of Rouen, Mont-Saint-Aignan, Cedex 76821, France. ${ }^{3}$ University of Rouen, Rouen University Hospital, GRAM, Rouen, EA 2656, France. ${ }^{4}$ Department of Microbiology, Hospital Clinic, Barcelona, Spain.

Received: 25 September 2013 Accepted: 25 February 2014

Published: 12 March 2014

\section{References}

1. Dijkshoorn L, Nemec A, Seifert H: An increasing threat in hospitals: multidrug-resistant Acinetobacter baumannii. Nat Rev Microbiol 2007, 5(12):939-951.

2. Rodriguez-Bano J, Marti S, Soto S, Fernandez-Cuenca F, Cisneros JM, Pachon J, Pascual A, Martinez-Martinez L, McQueary C, Actis LA, Vila J, Spanish Group for the Study of Nosocomial Infections (GEIH): Biofilm formation in Acinetobacter baumannii: associated features and clinical implications. Clin Microbiol Infec 2008, 14(3):276-278.

3. Giannouli M, Antunes LC, Marchetti V, Triassi M, Visca P, Zarrilli R: Virulencerelated traits of epidemic Acinetobacter baumannii strains belonging to the international clonal lineages I-III and to the emerging genotypes ST25 and ST78. BMC Infect Dis 2013, 13:282.

4. Bentancor LV, O'Malley JM, Bozkurt-Guzel C, Pier GB, Maira-Litran T: Poly-Nacetyl-beta-(1-6)-glucosamine is a target for protective immunity against Acinetobacter baumannii infections. Infect Immun 2012, 80(2):651-656.

5. Choi AH, Slamti L, Avci FY, Pier GB, Maira-Litran T: The pgaABCD locus of Acinetobacter baumannii encodes the production of poly-beta-1-6-Nacetylglucosamine, which is critical for biofilm formation. J Bacteriol 2009, 191(19):5953-5963.

6. Gaddy JA, Actis LA: Regulation of Acinetobacter baumannii biofilm formation. Future Microbiol 2009, 4(3):273-278.

7. Iwashkiw JA, Seper A, Weber BS, Scott NE, Vinogradov E, Stratilo C, Reiz B, Cordwell SJ, Whittal R, Schild S, Feldman MF: Identification of a general O-linked protein glycosylation system in Acinetobacter baumannii and its role in virulence and biofilm formation. PLoS Pathog 2012, 8(6):e1002758.

8. Mikkelsen H, Sivaneson M, Filloux A: Key two-component regulatory systems that control biofilm formation in Pseudomonas aeruginosa. Environ Microbiol 2011, 13(7):1666-1681.

9. Tomaras AP, Dorsey CW, Edelmann RE, Actis LA: Attachment to and biofilm formation on abiotic surfaces by Acinetobacter baumannii: involvement of a novel chaperone-usher pili assembly system. Microbiology 2003, 149(Pt 12):3473-3484.

10. Di Nocera PP, Rocco F, Giannouli M, Triassi M, Zarrilli R: Genome organization of epidemic Acinetobacter baumannii strains. BMC Microbiol 2011, 11:224. 
11. Marti S, Nait Chabane Y, Alexandre S, Coquet L, Vila J, Jouenne T, De E: Growth of Acinetobacter baumannii in pellicle enhanced the expression of potential virulence factors. PloS one 2011, 6(10):e26030.

12. Clemmer KM, Bonomo RA, Rather PN: Genetic analysis of surface motility in Acinetobacter baumannii. Microbiology 2011, 157(Pt 9):2534-2544.

13. Klausen M, Heydorn A, Ragas P, Lambertsen L, Aaes-Jorgensen A, Molin S, Tolker-Nielsen T: Biofilm formation by Pseudomonas aeruginosa wild type, flagella and type IV pili mutants. Mol Microbiol 2003, 48(6):1511-1524.

14. Cegelski L, Pinkner JS, Hammer ND, Cusumano CK, Hung CS, Chorell E, Aberg V, Walker JN, Seed PC, Almqvist F, Chapman MR, Hultgren SJ: Small-molecule inhibitors target Escherichia coli amyloid biogenesis and biofilm formation. Nat Chem Biol 2009, 5(12):913-919.

15. Hung DT, Shakhnovich EA, Pierson E, Mekalanos JJ: Small-molecule inhibitor of Vibrio cholerae virulence and intestinal colonization. Science 2005, 310(5748):670-674.

16. Shakhnovich EA, Hung DT, Pierson E, Lee K, Mekalanos JJ: Virstatin inhibits dimerization of the transcriptional activator ToxT. Proc Natl Acad Sci USA 2007, 104(7):2372-2377.

17. Magiorakos AP, Srinivasan A, Carey RB, Carmeli Y, Falagas ME, Giske CG, Harbarth S, Hindler JF, Kahlmeter G, Olsson-Liljequist B, Paterson DL, Rice LB, Stelling J, Struelens MJ, Vatopoulos A, Weber JT, Monnet DL: Multidrugresistant, extensively drug-resistant and pandrug-resistant bacteria: an international expert proposal for interim standard definitions for acquired resistance. Clin Microbiol Infec 2012, 18(3):268-281.

18. Marti S, Rodriguez-Bano J, Catel-Ferreira M, Jouenne T, Vila J, Seifert H, De E: Biofilm formation at the solid-liquid and air-liquid interfaces by Acinetobacter species. BMC Res Notes 2011, 4:5.

19. Wiegand I, Hilpert K, Hancock RE: Agar and broth dilution methods to determine the minimal inhibitory concentration (MIC) of antimicrobial substances. Nat Protoc 2008, 3(2):163-175.

20. OToole GA, Kolter R: Initiation of biofilm formation in Pseudomonas fluorescens WCS365 proceeds via multiple, convergent signalling pathways: a genetic analysis. Mol Microbiol 1998, 28(3):449-461.

21. Benoit MR, Conant CG, lonescu-Zanetti C, Schwartz M, Matin A: New device for high-throughput viability screening of flow biofilms. Appl Environ Microbiol 2010, 76(13):4136-4142.

22. McQueary CN, Actis LA: Acinetobacter baumannii biofilms: variations among strains and correlations with other cell properties. J Microbiol 2011, 49(2):243-250.

23. Wang S, Parsek MR, Wozniak DJ, Ma LZ: A spider web strategy of type IV pili-mediated migration to build a fibre-like Psl polysaccharide matrix in Pseudomonas aeruginosa biofilms. Environ Microbiol 2013, 15(8):2238-2253.

doi:10.1186/1471-2180-14-62

Cite this article as: Nait Chabane et al:: Virstatin inhibits biofilm

formation and motility of Acinetobacter baumannii. BMC Microbiology 2014 14:62

\section{Submit your next manuscript to BioMed Central and take full advantage of:}

- Convenient online submission

- Thorough peer review

- No space constraints or color figure charges

- Immediate publication on acceptance

- Inclusion in PubMed, CAS, Scopus and Google Scholar

- Research which is freely available for redistribution 